\title{
Using NDVI to Measure Precipitation in Semi-Arid Landscapes
}

\author{
Amy N Birtwistle ${ }^{a}$, Melinda Laituri ${ }^{a}$, Brian Bledsoe $^{b}$ and Jonathan M. Friedman ${ }^{c}$ \\ a Ecosystems, Science and Sustainability, Colorado State University, Fort Collins, CO 80523; \\ amy.birtwistle@gmail.com and melinda.laituri@colostate.edu \\ b College of Engineering, The University of Georgia, Athens, GA 30602; bbledsoe@uga.edu \\ c US Geological Survey, 1250 Centre Avenue, Bldg. C, Fort Collins, CO 80526; friedmanj@usgs.gov
}

\begin{abstract}
Measuring precipitation in semi-arid landscapes is important for understanding the processes related to rainfall and run-off; however, measuring precipitation accurately can often be challenging especially within remote regions where precipitation instruments are scarce. Typically, rain-gauges are sparsely distributed and research comparing rain-gauge and RADAR precipitation estimates reveal that RADAR data are often misleading, especially for monsoon season convective storms. This study investigates an alternative way to map the spatial and temporal variation of precipitation inputs along ephemeral stream channels using Normalized Difference Vegetation Index (NDVI) derived from Landsat Thematic Mapper imagery. NDVI values from 26 years of pre- and post-monsoon season Landsat imagery were derived across Yuma Proving Ground (YPG), a region covering $3,367 \mathrm{~km}^{2}$ of semiarid landscapes in southwestern Arizona, USA. The change in NDVI from a pre- to post-monsoon season image along ephemeral stream channels explained $73 \%$ of the variance in annual monsoonal precipitation totals from a nearby rain-gauge. In addition, large seasonal changes in NDVI along channels were useful in determining when and where flow events have occurred.
\end{abstract}

\section{Keywords}

Normalized Difference Vegetation Index (NDVI), Yuma Proving Ground, Landsat TM, Sonoran Desert, monsoon season, ephemeral stream channels 


\section{Introduction}

Plant growth in the semi-arid landscapes of southwestern North America is strongly dependent upon local and infrequent precipitation usually delivered from monsoon season storms (Huxman et al., 2004; Sutfin et al., 2014). Measuring the quantity and spatial and temporal distribution of precipitation is necessary for understanding the abiotic and biotic components within these landscapes. Rain gauges measure precipitation with high local precision, but gauges are sparse relative to the spatial variability of precipitation in the American southwest (Adams \& Comrie, 1997; Goodrich et al., 2008; Petrie et al., 2014). The advent of weather radar approximately 25 years ago allowed for spatially continuous precipitation data, but methodological changes over time complicate observation of trends over multiple decades (Hardegree, et al., 2008). In addition, accuracy is often contingent upon the storm type, the height of the radar beam, and topography, making radar data, at times, unreliable, especially in earlier versions (Kitzmiller et al., 2013; Birtwistle, 2015). In water-limited systems where the relationship between precipitation influence and vegetation response is robust, precipitation may indirectly be measured through satellite imagery to improve upon the discrepancy in spatial and temporal datasets (Wang et al., 2003; Barbosa et al., 2006; Méndez-Barroso et al., 2009; Barbosa \& Lakshmi Kumar., 2016). During periods of convective monsoon season storms, high-intensity precipitation events tend to generate run-off (Snyder \& Tartowski, 2006; Shaw \& Cooper, 2007; Lichvar et al., 2009; Svoray \& Karnieli, 2011), and strong transmission losses within the ephemeral stream channels keeps these run-off events local (Goodrich et al., 2008). Riparian vegetation along these channels maintain higher densities that can register a response to precipitation and runoff visible in satellite imagery.

Not all rain events produce enough precipitation to generate a noticeable vegetation response in satellite imagery. The fraction of rain that is available to plants varies depending on the type, quantity, 
and timing of precipitation (Brooks et al., 2011). Small rain events $(<2 \mathrm{~mm})$ may only influence the microbial community which aids in the production of carbon and nitrogen that are necessary for other biological processes (Collins et. al., 2008). Some plants such as summer annuals will only respond to substantial rain events such as pulse events that may initiate growth, while other vegetation responds primarily to cumulative rain events (Ogle \& Reynolds, 2004). While upland plants are too small and sparse to register a response to precipitation visible in satellite imagery, larger plants and higher vegetation densities that exist along ephemeral stream channels where runoff is concentrated (Shaw \& Copper, 2008) have the ability to see such changes. The response of vegetation cover to precipitation may not be linear over wide ranges of variation in precipitation. For example, when precipitation increases beyond a certain point, vegetation cover may no longer increase, since water is no longer the limitation to growth (Méndez-Barroso et al. 2009). The variation in precipitation quantities and frequencies can have profound effects on the vegetation composition over annual and decadal intervals (Snyder \& Tartowski, 2006). In this respect, inter- and intra-annual climatic variability can support a diverse set of vegetation, i.e. herbaceous plant seeds can endure for multiple years until the right conditions exist to initiate growth (Bowers et al., 2004) or significant flood events can promote tree recruitment and seedling success (Friedman \& Lee, 2002).

Remote sensing imagery is frequently used in studies that investigate and classify vegetation spatially and temporally. Landsat 5 TM has demonstrated its efficacy through its longevity, moderate spatial and temporal resolution, multispectral sensors and availability to the public. For these reasons, Landsat 5 TM has been widely and successfully used as a tool in research studies, including vegetation classification and change detection (Kerr \& Ostrobsky, 2003), vegetation health (Vogelmann et al., 2009), long-term land cover analyses (Nguyen et al., 2014; Wang et al., 2003), and ecosystem responses (Pettorelli et al., 2005; Barbosa et al., 2006; Méndez-Barroso et al., 2009; Barbosa \& Lakshmi Kumar., 2016). Normalized Difference Vegetation Index (NDVI), which uses the Red and Near Infrared (NIR) bands, can be explicitly related to vegetation productivity (Richard \& Poccard, 1998; Ichii et al., 2002; Pettorelli et al., 2005; Brooks et al., 2011) and precipitation influences (Nicholson \& Farrar, 1994; Wang et al., 2003; Barbosa et al., 2006; Barbosa \& Lakshmi Kumar., 2016).

The objective of this research was to determine if changes in vegetation measured via satellite imagery can be used to quantify the highly variable and localized precipitation inputs along ephemeral stream channels in the Sonoran desert. If proven acceptable, NDVI from Landsat TM imagery could be used where radar or rain-gauge data are unavailable or unreliable and could be extended to other arid 


\section{Study Site}

This research took place at the Department of Defense (DoD) installation, Yuma Proving Ground (YPG; Figure 1), located within the Sonoran Desert in southwestern Arizona, USA. YPG encompasses $3,367 \mathrm{~km}^{2}$ of semi-arid landscape with elevations ranging from 54 to $870 \mathrm{~m}$. During two separate rainy seasons - monsoon and winter, YPG receives an average total of $95 \mathrm{~mm} / \mathrm{yr}$ of precipitation (Western Regional Climate Center, 2012). This bimodal pattern leads to scattered rain events throughout the year, supporting a unique and diverse plant community that can include larger woody species, such as ironwood (Olneya tesota), paloverde (Parkinsonia spp.), acacia (Acacia greggi), and mesquite (Prosopis spp.), as well as columnar cacti (Sutfin et al., 2014). Sutfin et al. (2014) describe five general channel types that occur within this area: piedmont headwaters, bedrock, bedrock with alluvium, incised alluvium, and braided channel types. These stream types can be differentiated by the channel geometry, width-to-depth ratio, slope, stream power, and shear stress and have a fundamental influence on the vegetation (Sutfin et al., 2014).

Summer precipitation is driven by monsoon rains producing localized, high intensity storms that are influenced by topography. The American monsoon season develops from warm air that forms over the 


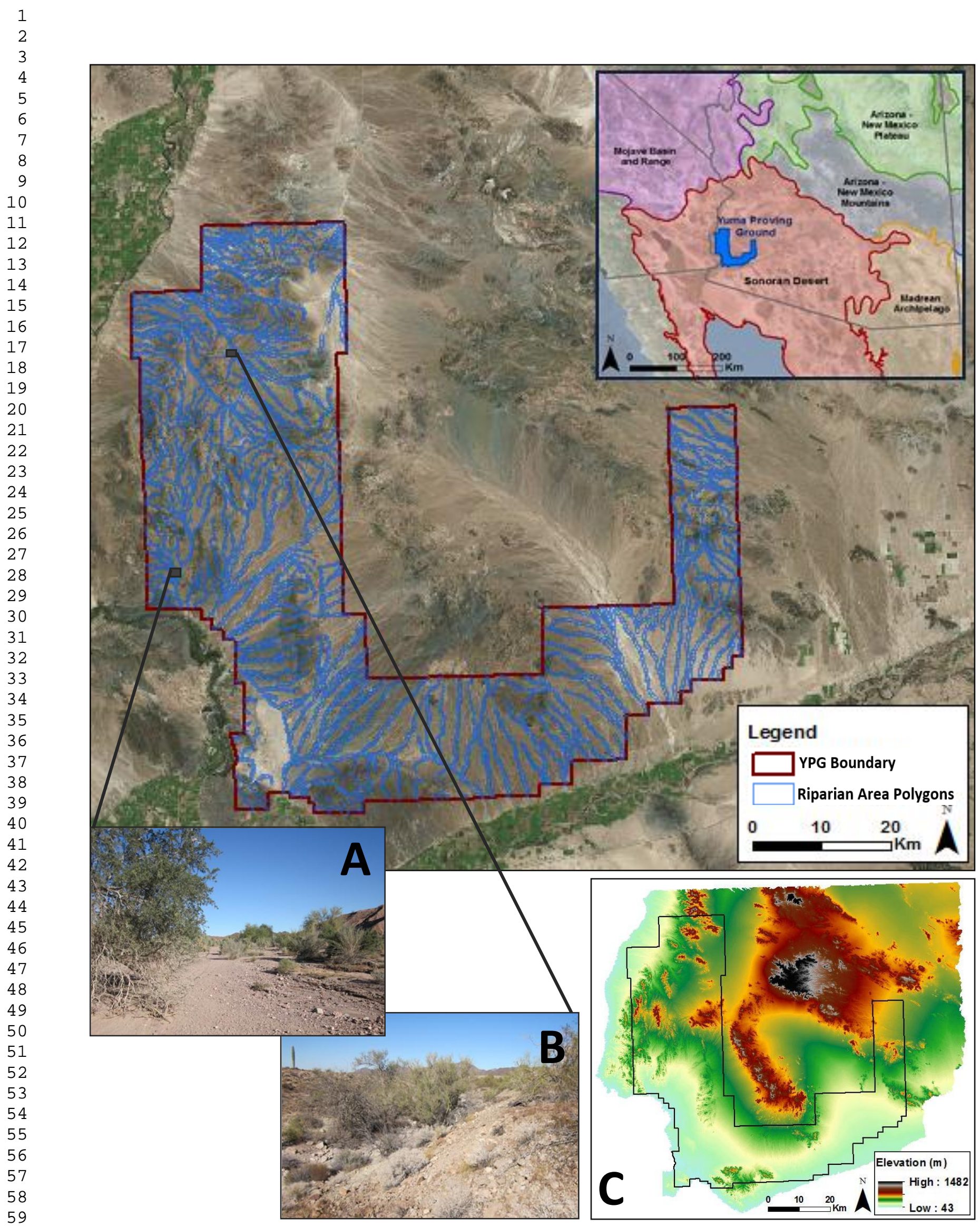

Figure 1: Location map of YPG within the Sonoran Desert. Inset A: Yuma Wash - Jan 2011 (UTMs: 11S $.3664132 \mathrm{~m} \mathrm{~N}, 731326 \mathrm{~m}$ E). Inset B: Mohave Wash - Jan 2011 (UTMs: 11S 3698644m N, 737959m E). 

Pacific Ocean and Gulf of California (Adams \& Comrie, 1997). The moist air mass typically moves north into northwestern Mexico and Arizona then disperses outward, although variations in weather and the position of the midtropospheric subtropical ridge lead to high variability in monsoon season precipitation (Adams \& Comrie, 1997). Large swaths of desert pavement coupled with low vegetation densities within the uplands allow rain water to move easily into stream channels, producing short-lived flow events. In contrast, winter precipitation typically originates from frontal storms that develop over the Pacific Ocean and tend to deliver more widespread, less intense, and longer-lasting rain events, leading to higher infiltration rates with less run-off (Snyder \& Tartowski, 2006; Stromberg et al., 2007). Many plant and animal species rely on the combination of these two rainy seasons that result in varying degrees of dependence. In this paper, we focus on using vegetation to quantify monsoon season precipitation because its high spatial variability is especially problematic for quantification by the limited rain-gauge network (Birtwistle, 2015).

\section{Materials and Methods}

The methods applied in this research are summarized in Figure 2. Riparian areas influenced by precipitation and flow were delineated across YPG and were used to isolate NDVI values. NDVI values were processed from each Landsat image over a period of 26 monsoon seasons. For each monsoon season, the pre- and post-monsoonal NDVI scenes were overlaid to create the change in NDVI scene ( $\triangle$ NDVI-S). The mean NDVI value of the top ten percent of pixel values (MTT) within each Riparian Area Polygon (RAP) unit were extracted from each $\triangle$ NDVI-S and were used to analyze the relationship between precipitation and the production of plant biomass. The change in MTT values was related to annual monsoon precipitation using rain-gauge data to assess the effectiveness of this dataset. In addition, we examined temporal variation in the vegetation response to two large precipitation events by examining NDVI of multiple images before and after each event. These methods are detailed below.

\subsection{Riparian Area Polygons (RAPS)}

RAPs were derived from the NHDPlus Version 2 flowlines layer for the Lower Colorado Vector Processing Unit (www.horizon-systems.com/NHDPlus/ NHDPlusV2 15.php). The NHDPlus Version 2 flowline network was split into 2,843 reaches of approximately $1 \mathrm{~km}$ or smaller lengths. This length was a compromise between the needs to create relatively uniform reaches and to limit study reaches to a 


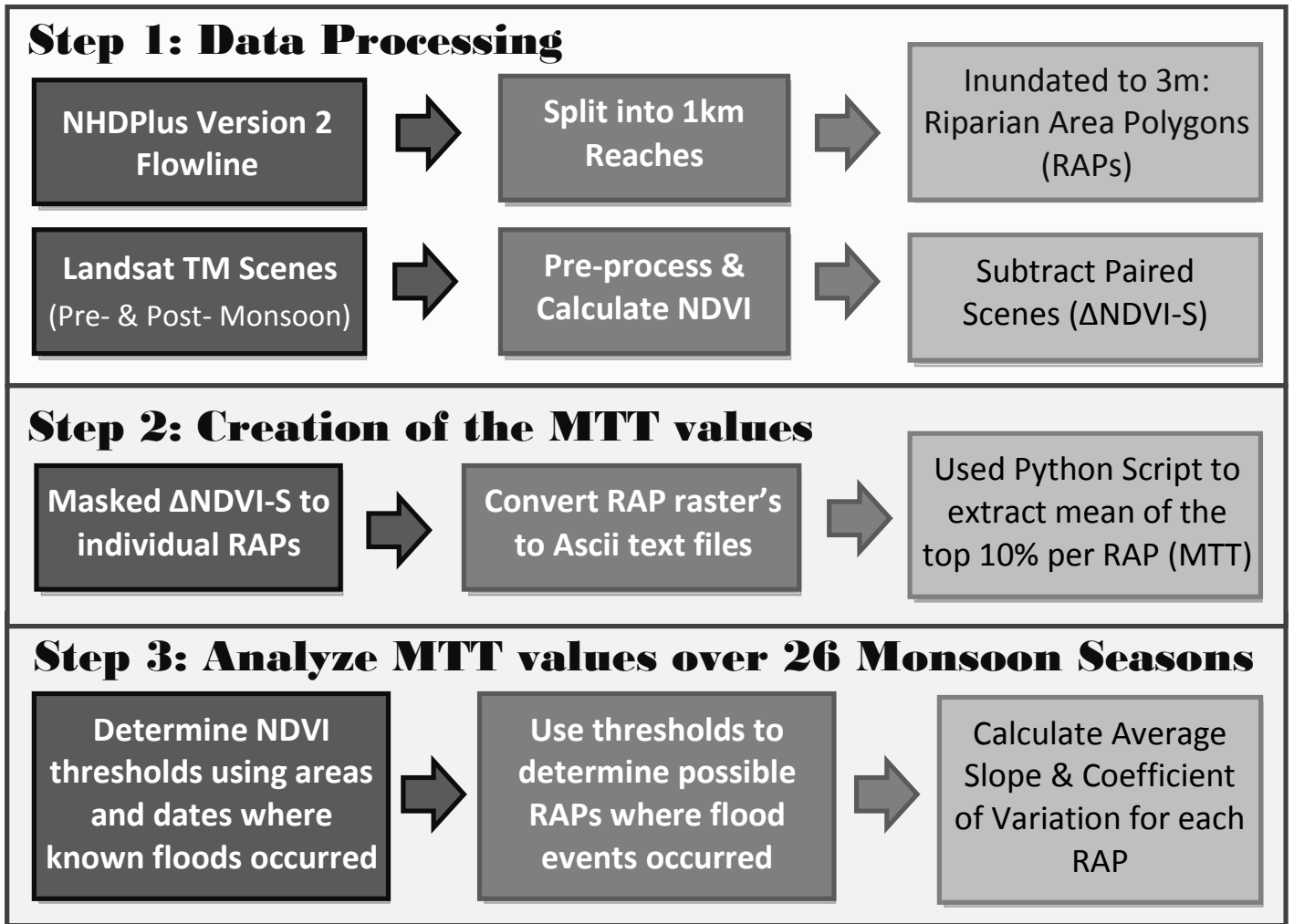

Figure 2: Flow Chart of Methods divided among three main steps.

manageable number. This layer was also used in the SERDP RC-1727 grant funded project (Levick et al., 2015). The inundated area of each reach was mapped as the smaller of two polygons: either the area within $200 \mathrm{~m}$ of the flowline or the area less than $3 \mathrm{~m}$ above the flowline determined using a $10 \mathrm{~m}$ DEM and the HGVC (Hydro-Geomorphic Valley Classification) extension tool (Carlson E.A., 2009) in ESRI ArcMap 10.2.

\subsection{Landsat TM}

Landsat TM scenes from Path 38, Row 37 were acquired through USGS's GlobeVis website (http://glovis.usgs.gov/) for pre- and post-monsoon season dates for years 1986 - 2011 (26 total). Landsat 5 TM images were used in all cases except during the 2000-02 monsoon seasons where Landsat 7 TM data provided superior image quality. Additional scenes were acquired for the 1989 (Landsat 5 TM) and 2013 (Landsat 8 TM) monsoon seasons to relate the change in NDVI to recorded flow events.

Each Landsat scene underwent pre-processing in ENVI 5.0 for Radiometric Calibration for Reflectance and Dark Object Subtraction. Landsat scenes were masked to the study area so that pixels were spatially aligned, and cell size was reduced to $5 \mathrm{~m}^{2}$ to ensure that smaller RAPs would capture all NDVI values. 
Resampling methods and pixel unmixing techniques were not used as it was probable that only highly vegetated pixels were included in the MTT values described below. NDVI values were calculated for individual scenes using the standard equation [(NIR - RED) / (NIR + RED)] in ESRI

ARCMap 10.2. Other indices were considered, but since this research isolated highly vegetative pixels, indices that performed better in regions of bare soil were not needed.

This includes Enhanced Vegetation Index (EVI; MéndezBarroso et al., 2009) and the Modified Soil Adjusted Vegetation Index (MSAVI; Qi et al., 1994). EVI or MSAVI could be used following similar methods and will enhance the analysis when using coarser resolution remote sensing platforms where bare soil is most abundant. Table 1 documents the dates of the pre- and post-monsoon season scenes chosen for each year. The Landsat scenes selected were influenced by the amount of cloud cover and were based on bracketing the monsoon season, which typically falls between July and September at YPG. The number of days between pre- and post-monsoon imagery had a mean of 103 days, a standard deviation of 17.7 days, and ranged from 60 to 160 days. The monsoon season NDVI base scene Table 1: Acquisition dates of Landsat TM and number of days between pre- and postmonsoon season images for each year.

\begin{tabular}{|c|c|c|c|}
\hline Year & \# Days & Pre- & Post- \\
\hline 1986 & 128 & June 15 & Oct 21 \\
\hline 1987 & 112 & June 18 & Oct 8 \\
\hline 1988 & 112 & June 4 & Sep 24 \\
\hline 1989 & 96 & June 23 & Sep 27 \\
\hline 1990 & 128 & May 25 & Sep 30 \\
\hline 1991 & 96 & June 29 & Oct 3 \\
\hline 1992 & 112 & June 15 & Oct 5 \\
\hline 1993 & 96 & July 4 & Oct 8 \\
\hline 1994 & 96 & July 7 & Oct 11 \\
\hline 1995 & 96 & June 8 & Sep 12 \\
\hline 1996 & 160 & May 9 & Oct 16 \\
\hline 1997 & 96 & July 15 & Oct 19 \\
\hline 1998 & 112 & June 16 & Oct 6 \\
\hline 1999 & 96 & June 3 & Sep 7 \\
\hline 2000 & 96 & June 13 & Sep 17 \\
\hline 2001 & 96 & June 16 & Sep 20 \\
\hline 2002 & 96 & June 19 & Sep 23 \\
\hline 2003 & 96 & June 14 & Sep 18 \\
\hline 2004 & 96 & July 2 & Oct 6 \\
\hline 2005 & 112 & June 19 & Oct 9 \\
\hline 2006 & 96 & June 22 & Sep 26 \\
\hline 2007 & 96 & June 25 & Sep 29 \\
\hline 2008 & 112 & June 11 & Oct 1 \\
\hline 2009 & 112 & June 30 & Oct 20 \\
\hline 2010 & 64 & July 3 & Sep 5 \\
\hline 2011 & 80 & June 20 & Sep 8 \\
\hline
\end{tabular}
was subtracted from the post-monsoon season NDVI imagery of that year creating the $\triangle$ NDVI-S, where positive values indicate a gain in NDVI. All $\triangle$ NDVI-S's are shown in the Supplementary Material.

\subsection{Mean of the Top Ten Percent (MTT)}

The mean value of the pixels above the $90^{\text {th }}$ percentile within each RAP unit was determined for each of the $26 \Delta$ NDVI-S. This was executed by masking individual 2,843 RAP units to each of the $26 \Delta$ NDVI-S and changing the newly created RAP raster images into ASCIl text files. A Python script was used to extract all NDVI values from each RAP ASCII text file and calculate the MTT value (Figure 2, Step 2). An example of this technique is demonstrated in Figure 3. The $90^{\text {th }}$ percentile was chosen to characterize the increase in NDVI because the RAP units typically incorporated 50 to $500,30 \times 30 \mathrm{~m}$ pixels, many of 
Figure 3: Figures $A$ and $B$ demonstrate the methods for extracting the MTT NDVI values within each RAP. For each $\triangle$ NDVI-S, each RAP was extracted separately by using individual RAP shapefiles in ArcMap 10.2 (Figure A), then converted into an ASCII text file that contains every pixel value within the RAP. The values of the pixels representing the Top $10 \%$ are depicted in Figure B. These values were extracted from the ASCII text file using a Python script and the MTT was calculated. This was done for every $\triangle$ NDVI-S at every RAP unit.

which are non-vegetated. Using any value less than the $90^{\text {th }}$ percentile would bias the results towards non-vegetated or partly-vegetated pixels because of the low vegetation densities seen at YPG. Using the maximum pixel value would misrepresent the increase in NDVI of the entire RAP; therefore the mean of the top ten percent was selected for analysis. Future applications could change the percentile within the Python script depending upon vegetation densities or landscape characteristics.

To summarize the MTT values, the change in NDVI per day (slope) was calculated for each RAP by dividing the $\triangle$ NDVI-S by the number of days between pre- and post-monsoon season imagery. Coefficient of variation (CV) was calculated for each RAP by dividing the standard deviation of the 26 years of MTT values by the mean.

\subsection{Rain-Gauge Data}

Daily precipitation data were obtained for 11 rain-gauge sites and were downloaded through the National Weather Service Forecast Center (http://www.wrh.noaa.gov/twc/monsoon/monsoon yum.php; Yuma) and the NOAA National Climatic Data Center website (http://www.ncdc noaa.gov/dataaccess/land-based-station-data; $N C D C$ ). Six locations within and surrounding YPG (Figure 4: crosses) 
covered most of the 26-year study period with few gaps. A second group of five rain-gauges was acquired for Yuma (YBA, YBD and YIA) and Mohave washes (MBD and MBA; Figure 4: drops) for 2011-13 (Faulconer, 2015).

The MTT values from 52 RAPs surrounding the rain-gauge 3125 were associated to the precipitation record from this rain-gauge for each monsoon season between 1986 and 2011 (Results \& Discussion: Figure 6). Raingauge 3125 lacked data on two dates in 1988 (June 20 \& August 31) and much of 2009. To accommodate these missing data, 2009 was dropped from the analysis and we assumed

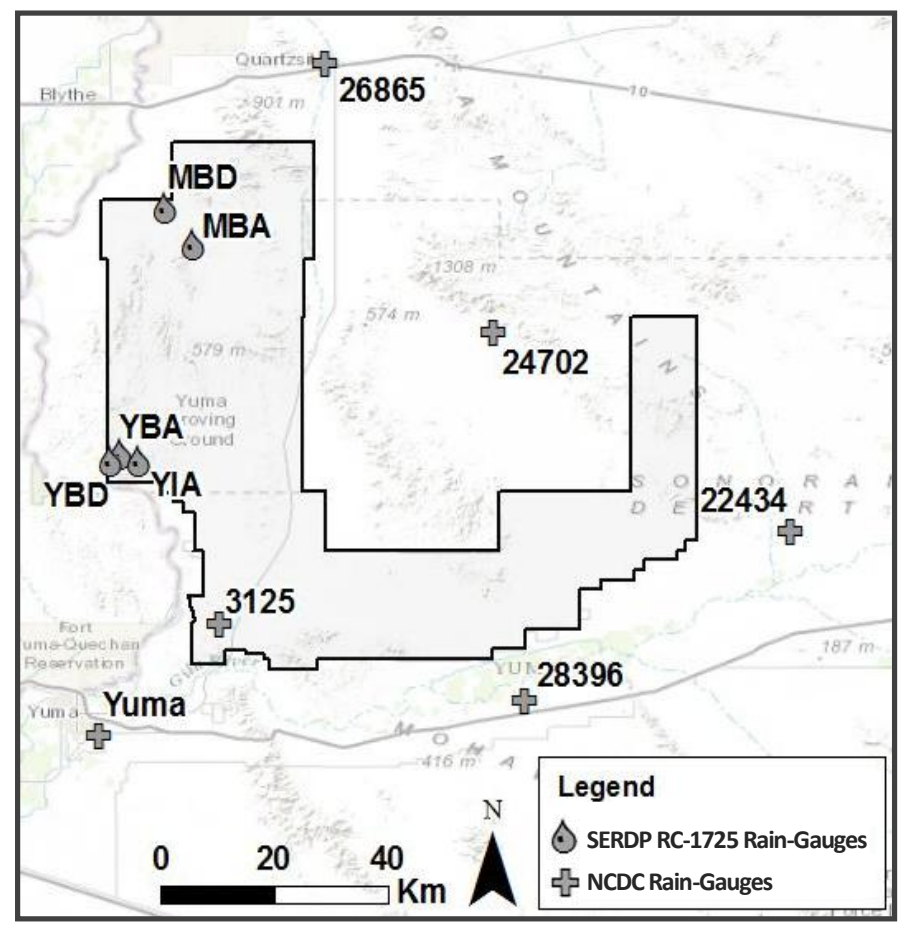

Figure 4: Rain-gauges distributed in the YPG vicinity. that there was no precipitation recorded on the unknown 1988 dates as the surrounding gauges did not register precipitation. The RAPs within $11 \mathrm{~km}$ of the rain gauge were isolated. Using RAPs within four separate drainages was a way to minimize local biases. Larger storms that would increase flow in the lower RAPs may have favored the results to show larger increases in MTT values when compared to the precipitation data; but losing stream types would likely cancel or lessen the increase in MTT. Nevertheless, this gauge was chosen because of its long-term record that coincided with the study area and the 52 RAPs were used to show the relationship between precipitation and the MTT values regardless of site specific details. Linear regression analysis was performed in RStudio 3.1.1 (R Core Team, 2014) over the 25 monsoon seasons using the precipitation and MTT data. Precipitation was totaled between the pre- and post-monsoon season dates for each season; however, to account for a time-lag between rainfall and vegetation growth, precipitation recorded within the 12 days prior to the post-Monsoon season date was excluded. The twelve-day lag was selected based on the findings of Svoray \& Karnieli (2011) who showed that a lag of one week to one month existed between rainfall and increase in NDVI. Their study took place in similar vegetation, although during the cold season; thus a relatively small interval was selected since plants typically grow faster during warmer months. 


\section{Results \& Discussion}

Variation among years in NDVI are consistent with inter-annual variation in monsoonal precipitation (Figures 5 and 6). A negative change in NDVI indicates that there was little or no rain and/or that persistent higher temperatures caused noticeable decreases in plant productivity. A zero or near zero change indicates that few rainfall events occurred and that vegetation did not change in the pixelated area. A positive change indicates that rainfall contributed to an increase in plant productivity and a large positive increase in NDVI suggests that the riparian area may have been influenced by a flow event or several significant rain events. When flow events occur, downstream vegetation responds to precipitation that falls not only locally, but in upstream and upland features. As a result, the correlation lessens in using plants as active rain-gauges.

The years 1986, 1988, 1990 and 1997 had higher than average changes in NDVI, with median MTT values for all RAP units at $0.049,0.052,0.047$, and 0.077 , respectively (Figure 5 ). The large change in the MTT values seen in 1997 is likely due to the strong and rapid increase in El Niño conditions that occurred prior to the 1997 monsoon season (NOAA, n.d.). The maximum MTT value for an individual RAP unit was 0.342 in the southeastern portion of YPG during the 1999 monsoon season. In contrast, the MTT values from the 2005 monsoon season (Figure 5) shows a decrease in NDVI in several RAP units resulting from a fire that burned through a portion of YPG and the KOFA National Wildlife Refuge preserve to the north (Esque et al., 2013). The minimum MTT value during this year is -0.046 and serves as the lower limit of 


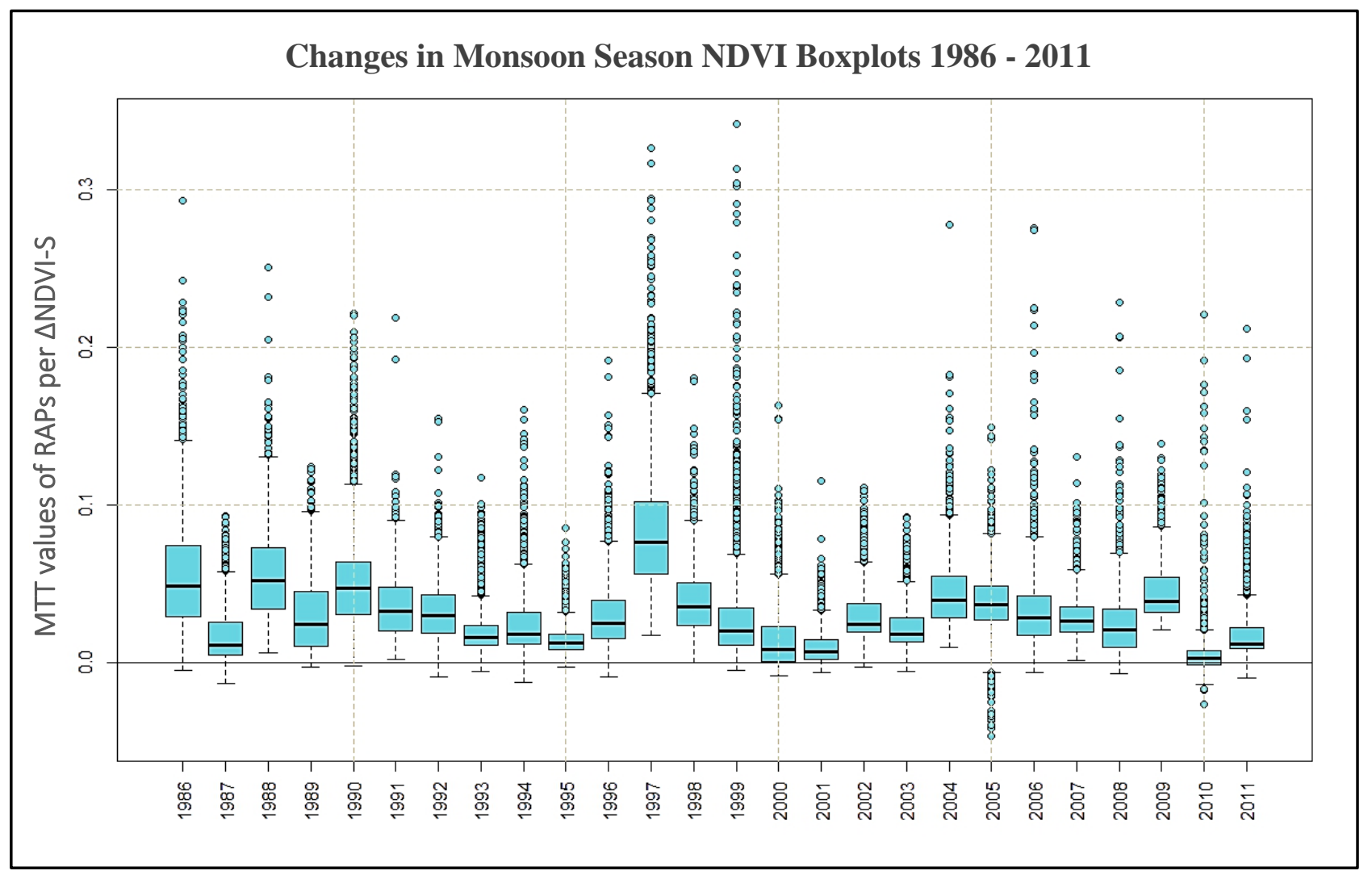

Figure 5: Boxplots for $\triangle$ NDVI-S along the 2,843 RAPs for all monsoon season study years.

the 1986-2011 dataset. A strong negative MTT change $(<-0.02)$ is atypical during the wet season and when observed, is likely the result of a significant land cover change. The negative MTT values in 2010 are likely an artifact of an early post-monsoon season image of September 5, 2010 (Table 1). Later images would have been preferable, but were unusable due to the extent of cloud cover over the study area. What is apparent from the cloud-free portions of the October 7, 2010 image is that the monsoon season appears to be more similar to other monsoon seasons than is depicted from the September 5 , 2010 image. This example illustrates the importance of selecting the best available dates while considering the extent of cloud cover versus the impact of change in NDVI. Other years that may be inflicted by earlier than optimal post-monsoon season imagery include 1995, 2001, 2003, and 2011. 


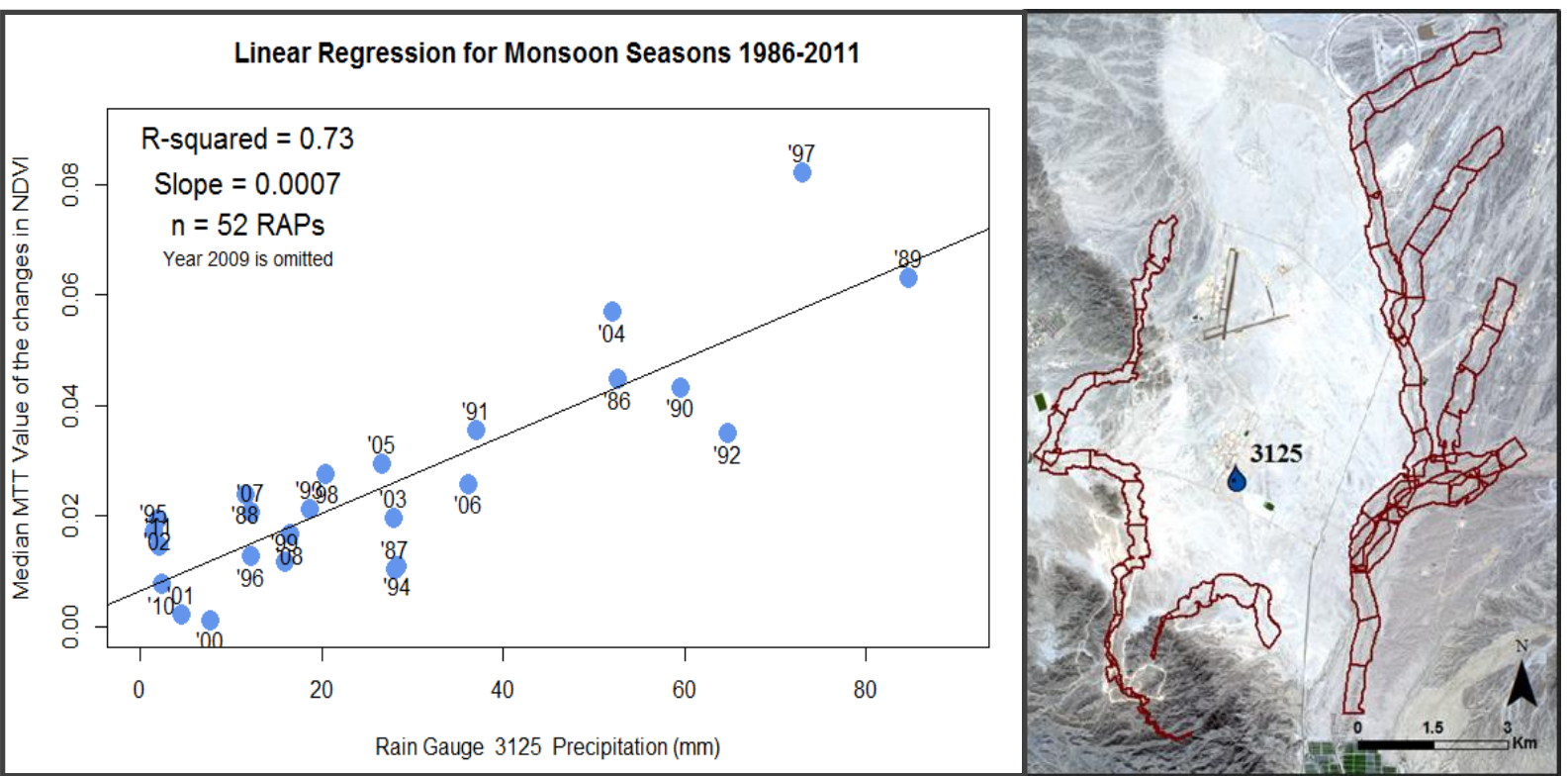

Figure 6: Linear regression comparing the total precipitation during monsoon seasons $1986-08$ and 2010-11 at rain-gauge 3125 to nearby RAPs. The median MTT value of the 52 RAPs were taken for every $\triangle N D V I-S$ and regressed on the precipitation totals at the rain-gauge.

For the 52 RAPs within 11-km of the rain gauge, the median MTT value of the change in NDVI for each year was strongly correlated with precipitation over the monsoon season (adjusted $R^{2}=0.73$; Figure 6). The slope of the linear regression (Figure 6) was found to be 0.0007 and indicates that $10 \mathrm{~mm}$ of rainfall will increase the MTT values by roughly 0.007 . There have been many studies that have established robust relationships between precipitation, plant productivity, and NDVI (Nicholson \& Farrar, 1994; Wang et al., 2003; Pettorelli et al., 2005; Barbosa et al., 2006; Brooks et al., 2011). In this study, we found a high correlation between the MTT values and rain-gauge data, demonstrating the feasibility of using NDVI to estimate precipitation at the seasonal scale.

To characterize the response of vegetation to precipitation events that generated flow we examined changes in NDVI following two intense rain events (Figures $7 \& 8$ ). A strong increase in the MTT values occurred following the precipitation and flow event on August 9, 1989 (Figure 7B). The Landsat scene taken on July 25,1989 prior to the event, documented only a slight increase of 0.0027 (slope $=0.0001$ ) in the median MTT values relative to the pre-monsoonal image for the 52 RAP units. The August 26, 1989 Landsat scene, saw an increase in the median of the MTT values by 0.057 , increasing the slope to 0.0017 $\triangle N D V I /$ day between July 25 and August 26, 1989 (Figure 7 A \& B). Following August 26, 1989, the increase in NDVI declined substantially to $0.0002 \Delta \mathrm{NDVI} /$ day for the next month and $0.0003 \Delta \mathrm{NDVI} /$ day over the following month. 
When relating these data to the entire monsoon season, the strong change in NDVI following a flow event is diluted (0.0006 $\Delta \mathrm{NDVI}$ /day increase between June 23 and Oct 29, 1989; Figure 7B), but the evidence of precipitation is still clear. For the monsoon season as a whole, a total of $84.7 \mathrm{~mm}$ of precipitation produced an overall change in the $\triangle$ NDVI values of 0.071 . The substantial increases in NDVI 
Figure 7: 1989 flow event and NDVI Comparison. The GHCN 3125 rain-gauge recorded a considerable rain event $(61 \mathrm{~mm})$ on August 9, 1989 (A). Increase in NDVI over a spatially large area indicates that this rain event covered a relatively large region (>15km; Landsat Plates). Changes in NDVI were recorded for 52 reaches during the 1989 monsoon season (B). The largest change in NDVI using the MTT values, occurred within the first $18 \mathrm{~d}$ following the flood event ( $s=0.0017)$. The average slope between Jun 23 and Oct 29 (128d) is 0.0006 .

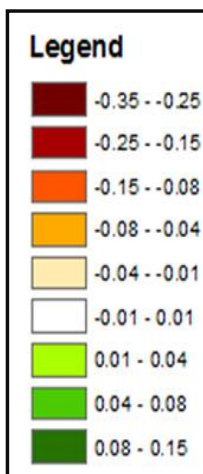

A

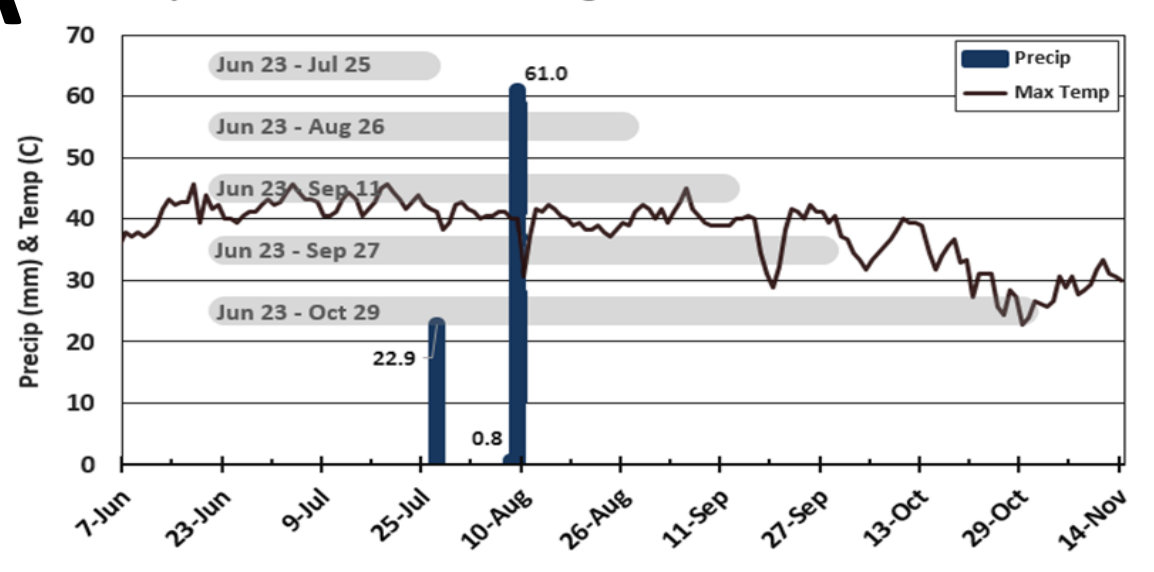

B

Change in MTT values following a large Rain Event

$0.10 n=52$ RAPs

$\mathrm{n}=52$ RAPs
Average slope: 0.0006

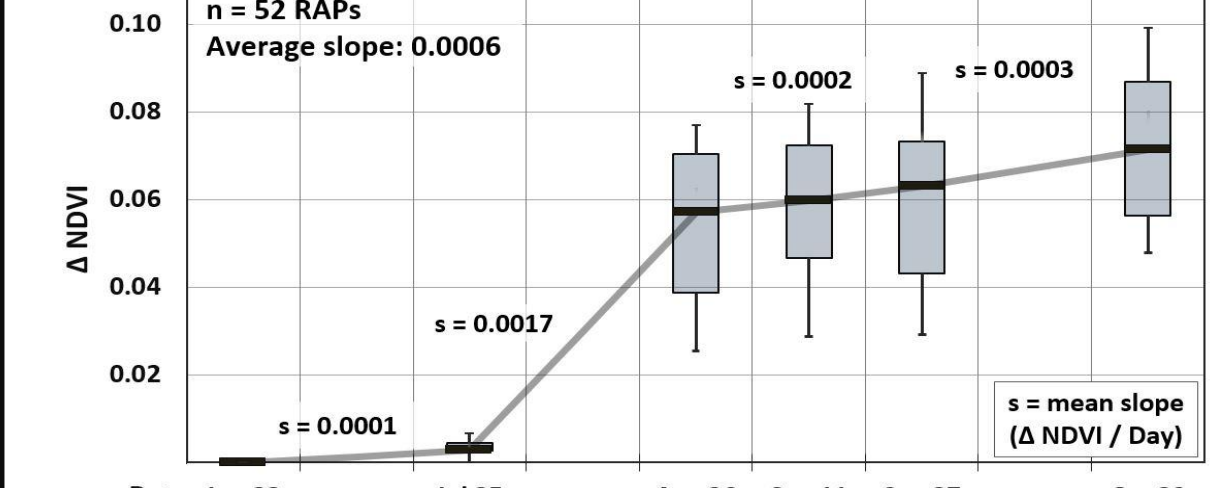

Post Rain Event:

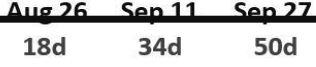

$82 d$

Jun 23 - Jul 25, 1989

\section{Landsat Plates}

.

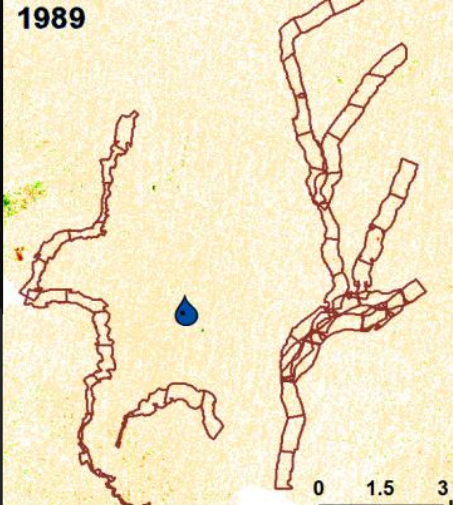

Jun 23 - Aug 26 ,

1989

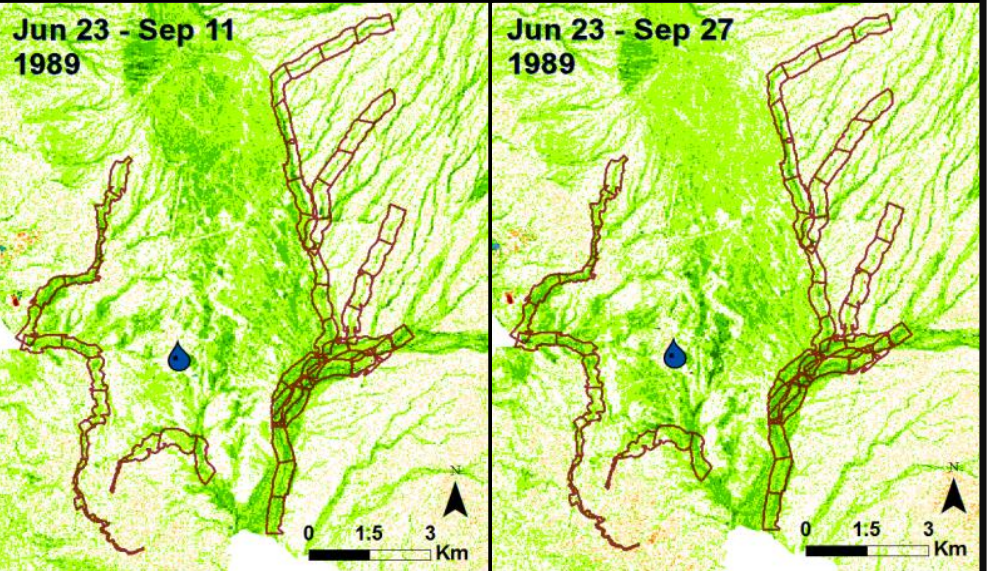

Jun 23 - Oct 29

1989 
during the monsoon season, can be used to identify locations where significant rain and/or flow events may have occurred.

Similar results are seen during the 2013 flow event at Mohave Wash using the median MTT values of the 10 closest RAP units (Figure 8). Unlike the 1989 event, the increase in NDVI within the surrounding area suggests that this event was considerably less extensive, and therefore only 10 RAPs were used to show the change in NDVI (Figure 8: Landsat Plates). Due to other rain events recorded during the 2013 monsoon season, the MTT values derived from the six Landsat scenes showed a sustained increase.

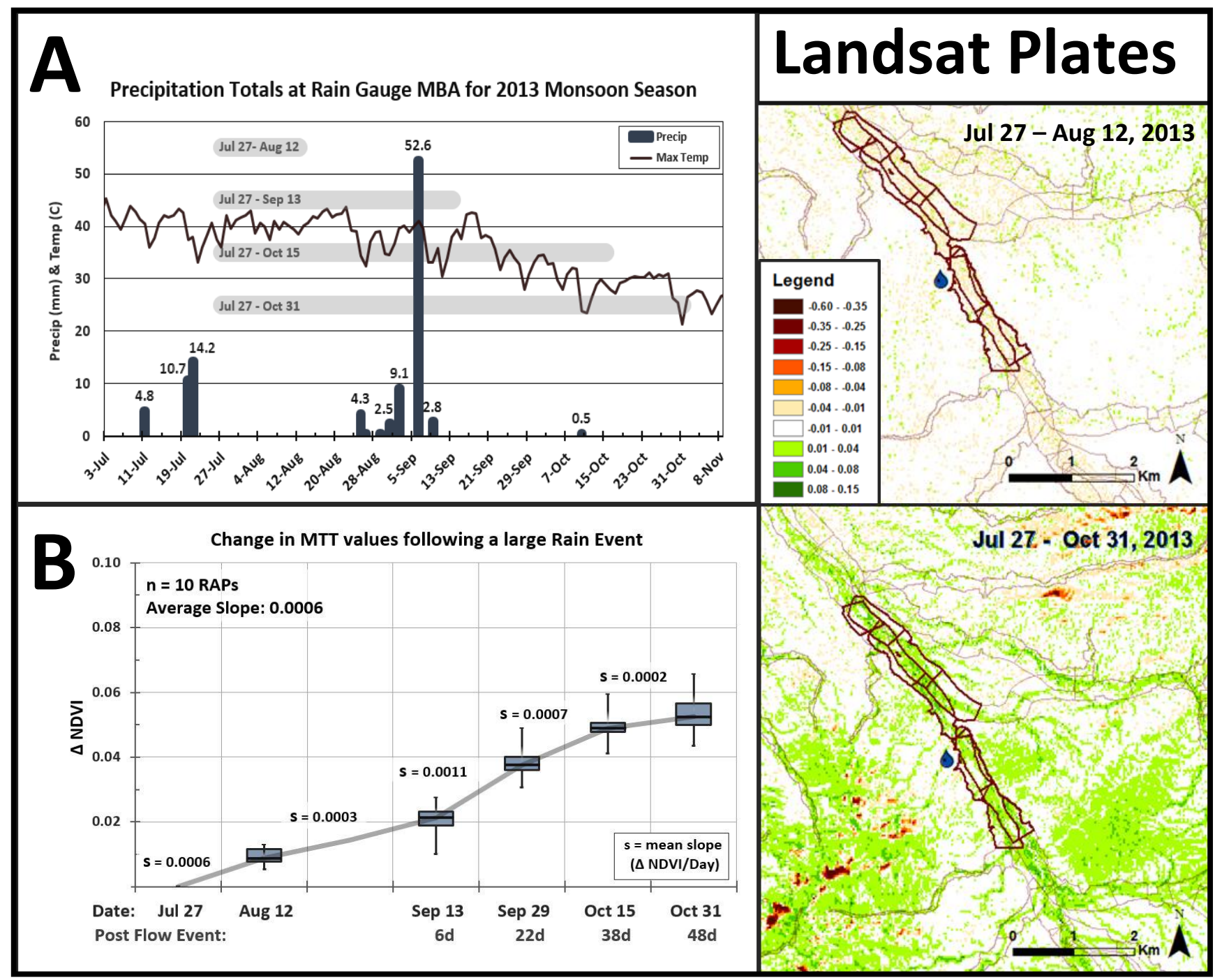

Figure 8: Mohave Wash (2013) flow event and NDVI Comparison. Rain-gauge data recorded a high precipitation event on September 7, $2013(52.6 \mathrm{~mm}$; A), soil moisture data and field observations in October of 2013 indicated a flow event (re-working of channel and debris found in channel). The largest increase in NDVI values were seen between 6 and 22 days following this event (slope $=0.0011$ ) and decreased to 0.0007 after 38d. The average slope between Jul 27 and Oct 31 (96d) is 0.0006 (B). 
Comparing the MTT values from September 13 and 29 ( 6 to $22 \mathrm{~d}$ following the flow event), the rate of increase rose from 0.0003 to $0.0011 \Delta \mathrm{NDVI} /$ day (Figure 8B). Between September 29 and October 15 (22 to $38 \mathrm{~d}$ following the event), the $\Delta \mathrm{NDVI} /$ day decreased to 0.0007 . After October 15 and 38 days following the flow event, the $\triangle \mathrm{NDVI} /$ day decreased considerably to 0.0002 . For the 2013 flow event, the NDVI between pre- and post-monsoon season images also increased by 0.0006 per day. During this season, a total of $101.5 \mathrm{~mm}$ of precipitation produced an overall change in NDVI of 0.052 . This less efficient response in vegetation per unit of rainfall may reflect the limited spatial extent of the precipitation.

Slopes ( $\triangle \mathrm{NDVI} /$ day) were calculated for all RAP units for each of the 26 Monsoon seasons. For this analysis, the ideal number of days between scenes is equal to 96 or 112 and accounts for 21 monsoon seasons (Table 1). Table 2 shows the percentage of RAPs with slopes above the $0.0006 \Delta \mathrm{NDVI} / \mathrm{day}$ threshold for each season. The largest percentage occurred in 1997 with over $73 \%$ of the RAPs surpassing the 0.0006 threshold. This suggests that not only were there significant rain events during this season, but the coverage was more uniform than is typical during the Monsoon season. Other notable years with higher percentages were 1998 at 31\%, 1986 at 23\%, 2004 at 21\%, 1989 and 1990 at 13\%, 2009 at $12 \%$ and 1999 at $11 \%$ (Table 2 ).

The slopes of the MTT values for each RAP were averaged over the 26 Monsoon seasons and are displayed in Figure 9A. Inclusion of the 2010 (only 64d between pre- and post- scenes) monsoon season did not Table 2: Percent of RAP units $>0.0006$ $\triangle \mathrm{NDVI} /$ day threshold per monsoon season. appreciably vary these results. RAP units with greater average slopes had more frequent increases in NDVI, suggesting that they received more monsoon season precipitation over the 1986 to 2011 study period. Of the $2,751 \mathrm{~km}$ of stream channels at YPG, approximately $8 \%$ had an average slope between 0.0001-0.0002, 43\% between $0.0002-0.0003,36 \%$ between $0.0003-0.0004$, $10 \%$ between $0.0004-0.0005$, and $3 \%$ between 0.0005 0.0010 . Figure $9 \mathrm{~A}$ shows that the mountainous terrain located in the western portions of YPG, tends to have on average greater changes in NDVI/day than in flatter terrain and also shows that as distance increases from Larger percentages are in bold.

\begin{tabular}{|c|c|c|c|}
\hline Year & \% $>\mathbf{0 . 0 0 0 6}$ & Year & $\mathbf{\%}>\mathbf{0 . 0 0 0 6}$ \\
\hline 1986 & $\mathbf{2 3 . 0}$ & 1999 & $\mathbf{1 1 . 1}$ \\
\hline 1987 & 1.0 & 2000 & 3.0 \\
\hline 1988 & $\mathbf{3 1 . 3}$ & 2001 & 0.2 \\
\hline 1989 & 13.0 & 2002 & 8.5 \\
\hline 1990 & $\mathbf{1 3 . 7}$ & 2003 & 3.4 \\
\hline 1991 & 1.3 & 2004 & $\mathbf{2 1 . 7}$ \\
\hline 1992 & 4.5 & 2005 & 5.6 \\
\hline 1993 & 4.4 & 2006 & $\mathbf{1 0 . 0}$ \\
\hline 1994 & 7.2 & 2007 & 4.0 \\
\hline 1995 & 0.5 & 2008 & 2.5 \\
\hline 1996 & 0.9 & 2009 & $\mathbf{1 2 . 1}$ \\
\hline 1997 & $\mathbf{7 3 . 5}$ & 2010 & 1.3 \\
\hline 1998 & 7.9 & 2011 & 6.5 \\
\hline
\end{tabular}



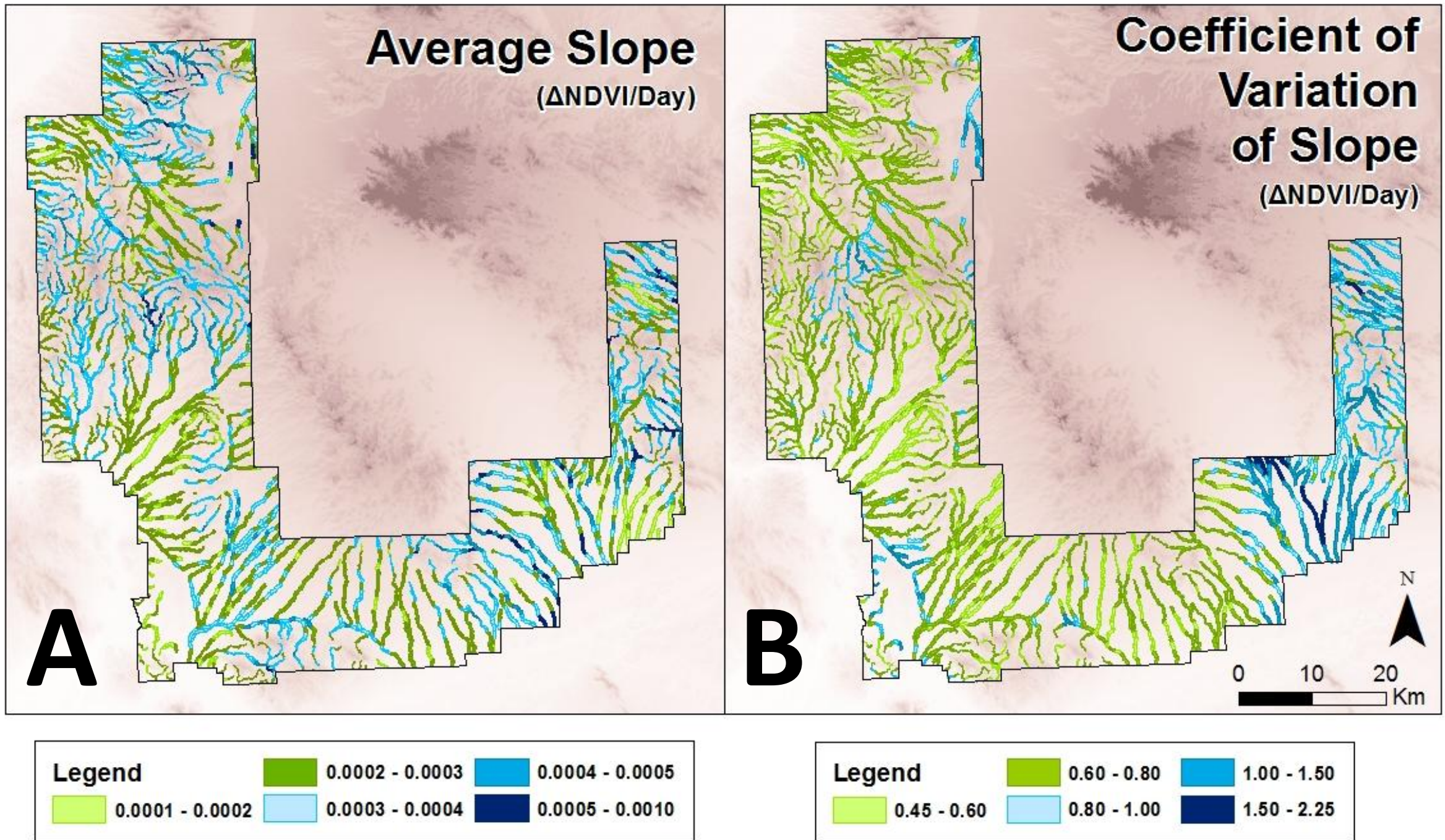

Figure 9: A: The slope ( $\triangle \mathrm{NDVI} /$ day) of the MTT values at each RAP were averaged over the 26 Monsoon seasons. A larger slope indicates that there were on average higher increases in NDVI at that reach over the 26 years. B: The Coefficient of Variation (CV; standard deviation/mean) indicates the variance of the MTT values over the timeframe. A $10 \mathrm{~m}$ DEM is set as the backdrop in both Figures. 
CV values describing the inter-annual variability in NDVI among RAPs at YPG are shown in Figure 9B. Lower $\mathrm{CV}$ values $(\mathrm{CV}<1)$ suggest that there have been smaller changes and higher values $(\mathrm{CV}>1)$ imply that the RAPs experienced greater changes in NDVI over the 26 year period. In general, the eastern portions of YPG have experienced more variability than the western portions. Some of the RAPs with a CV greater than 1.5 are in the region affected by the 2005 fire. This region is also a drainage for a large mountain range in the KOFA National Wildlife Refuge to the north and under the right conditions can experience large flow events. The distance of these channels from the mountains also causes this region to undergo relatively high transmission losses. This may explain why the southeastern portion of YPG sees higher variability in NDVI from 1986-2011 than in other regions. The mountainous region located in the western portion of YPG may see more consistent weather patterns due to orographic effects, thus depicting lower $\mathrm{CV}$ values.

Brooks et al. (2011) state that "translating changes in precipitation into changes in plant available water is not straightforward." Similarly, using NDVI to investigate precipitation influences is not exact and there are a variety of factors that can either increase or decrease NDVI throughout the monsoon season. Such factors may include contributing area as well as channel type, size of the storm, storm intensity (higher overland flow with stronger intensities), type of riparian vegetation (woody versus herbaceous), vegetation densities and antecedent conditions. Changes in landcover such as the loss of vegetation following the 2005 fire can also cause significant changes in NDVI that may misrepresent actual precipitation, unless the disturbance is accounted for. Moreover, the timing of the remote sensing imagery can play a major role in indicating when and where flood events have occurred when using this method. Landsat imagery has a 16-day temporal resolution and when cloud cover exists within the imagery the temporal resolution can increase to 32 or 48 days between usable scenes. Other remote sensing platforms may have shorter recurrence intervals, but these often suffer from coarser resolution or higher costs. Additionally, NDVI is only one of many indices. Other vegetation indices may show stronger correlation when compared to precipitation inputs or be more suitable in different climates and vegetation densities. Despite these limitations, the results of this study show that Landsat imagery can be used to show the spatial and temporal variability of monsoon season precipitation in semi-arid ecosystems. 


\section{Conclusions}

This study demonstrates that changes in riparian plant productivity derived from Landsat imagery can be used to estimate seasonal monsoon season precipitation in a semiarid region. Whereas upland plants were too small and sparse to provide a measurable response to rainfall, ephemeral stream channels concentrated local precipitation inputs, resulting in a quantitative response from vegetation measured as NDVI. Changes in NDVI derived from 26 years of Landsat TM imagery explained $73 \%$ of the variance in precipitation totals when compared directly to a nearby rain-gauge. In addition, strong increases in NDVI were a reliable indicator of the timing and location of flow events in these ephemeral channels.

We measured the response of vegetation to precipitation over a period of months. In contrast, rain gauges and radar are able to measure precipitation at scales as fine as minutes. At the seasonal time scale, however, using Landsat TM imagery to estimate precipitation in semi-arid regions has several advantages. Landsat TM imagery has spatial continuity superior to rain-gauge networks and a historical record extending to three decades. This approach can be used in water-limited systems globally, especially where rain gauge and radar data are rare and where a distinct rainy season exists. Furthermore, this method can extend to other remote sensing platforms and vegetation indices depending upon imagery resolution, site characteristics or vegetation densities.

\section{Acknowledgements}

We gratefully acknowledge support from the Department of Defense, Strategic Environmental Research and Development program (SERDP; www.serdg.org), under the Resource Conservation and Climate Change program area, project RC-1727. Special appreciation is directed towards Lainie Levick (USDA-ARS, Tucson, AZ), Samantha Hammer and Russell Lyon (University of Arizona), and Dr. Paul Evangelista, Dr. David Cooper, Joshua Faulconer, and Jeremy Shaw from Colorado State University for their support and guidance in this work. Eric Schmidt also deserves acknowledgment for his assistance in writing the Python script used in this research. 


\section{References}

Adams, D.K. and A. C. Comrie. 1997. The North American monsoon. Bulletin of the American Meteorological Society 78(10): 2197-2213. doi:http://dx.doi.org/10.1175/15200477(1997)078<2197:TNAM>2.0.CO;2

Barbosa, H. A., A. R. Huete and W. E. Baethgen. 2006. A 20-year study of NDVI variability over the northeast region of Brazil. Journal of Arid Environments 67(2):288-307. doi:10.1016j.jaridenv.2006.02.022.

Barbosa, H. A., and T. V. Lakshmi Kumar. 2016. Influence of rainfall variability on the vegetation dynamics over Northeastern Brazil. Journal of Arid Environments 124:377-387. doi:10.1016/j.jaridenv.2015.08.015.

Birtwistle, A. N. 2015. Linking riparian vegetation to precipitation using NDVI at Yuma Proving Ground, AZ. M. S. Thesis. Colorado State University. (https://dspace.library.colostate.edu/handle/10217/170347).

Bowers, J. E., R. M. Turner, and T. L. Burgess. 2004. Temporal and spatial patterns in emergence and early survival of perennial plants in the Sonoran Desert. Plant Ecology 172(1):107-119. doi:10.1023/B:VEGE.0000026026.34760.1b.

Brooks, P. D., P. A. Troch, M. Durcik, E. Gallo, and M. Schlegel. 2011. Quantifying regional scale ecosystem response to changes in precipitation: Not all rain is created equal. Water Resources Research 47(10). doi:10.1029/2010ER009762.

Brown, M. E., J. E. Pinzón, K. Didan, J. T. Morisette, and C. J. Tucker. 2006. Evaluation of the consistency of long-term NDVI time series derived from AVHRR, SPOT-Vegetation, SeaWiFS, MODIS, and Landsat ETM+ sensors. Geoscience and Remote Sensing, IEEE Transactions on 44(7):1787-1793. doi:10.1109/TGRS.2005.860205.

Collins, S. L., R. L. Sinsabaugh, C. Crenshaw, L. Green, A. Porras-Alfaro, M. Stursova, and L. H. Zeglin. 2008. Pulse dynamics and microbial processes in aridland ecosystems. Journal of Ecology 96(3):413420. doi:10.1111/j.1365-2745.2008.01362.x.

Esque, T. C., R. H. Webb, C. S. Wallace, C. van Riper III, C. McCreedy, and L. Smythe. 2013. Desert fires fueled by native annual forbs: effects of fire on communities of plants and birds in the lower Sonoran desert of Arizona. The Southwestern Naturalist 58(2):223-233. doi:10.1894/0038-4909-58.2.223.

Carlson, E. A. 2009. Fluvial riparian classification for national forests in the western United States. M.S. Thesis. Colorado State University.

Faulconer, J. D. 2015. Thresholds for run-off generation in ephemeral streams with varying morphology in the Sonoran desert in Arizona, USA. M. S. Thesis. Colorado State University.

Friedman, J. M., and V. J. Lee. 2002. Extreme floods, channel change, and riparian forests along ephemeral streams. Ecological Monographs 72(3):409-425. doi:10.1890/00129615(2002)072[0409:EFCCAR]2.0.CO;2.

Goodrich, D. C., C. L. Unkrich, T. O. Keefer, M. H. Nichols, J. J. Stone, L. R. Levick, and R. L. Scott. 2008. Event to multidecadal persistence in rainfall and run-off in southeast Arizona. Water Resources Research 44(5). doi:10.1029/2007WR006222. 

precipitation products for natural resource applications. Rangeland Ecology and Management 61:346-353. doi:10.2111/07-036.1.

Huxman, T. E., K. A. Snyder, D. Tissue, A. J. Leffler, K. Ogle, W. T. Pockman, D. R. Sandquist, D. L. Potts, and S. Schwinning. 2004. Precipitation pulses and carbon fluxes in semiarid and arid ecosystems. Oecologia 141(2):254-268. doi:10.1007/s00442-004-1682-4.

Huxman, T. E., G. Barron-Gafford, K.L. Gerst, A. L. Angert, A. P. Tyler and D. L. Venable. 2008. Photosynthetic resource-use and demographic variability in desert winter annual plants. Ecology 89(6):1554-1563. doi:10.1890/06-2080.1.

Ichii, K., A. Kawabata, and Y. Yamaguchi. 2002. Global correlation analysis for NDVI and climatic variables and NDVI trends: 1982-1990. International Journal of Remote Sensing 23(18):3873-3878. doi:10.1080/01431160110119416.

Kerr, J. T., and M. Ostrovsky. 2003. From space to species: ecological applications for remote sensing. Trends in Ecology \& Evolution 18(6):299-305. doi:10.1016/S0169-5347(03)00071-5.

Kitzmiller, D., D. Miller, R. Fulton, and F. Ding. 2013. Radar and multisensor precipitation estimation techniques in National Weather Service hydrologic operations. Journal of Hydrologic Engineering 18(2): 133-142. doi:10.1061/(ASCE)HE.1943-5584.0000523

Levick, L., S. Hammer, R. Lyon, J. Murray, A. Birtwistle, D. Goodrich, B. Bledsoe, P. Guertin, and M. Laituri. 2015. An ecohydrological approach to managing intermittent and ephemeral streams on Department of Defense lands in the southwestern United States. Department of Defense, Strategic Environmental Research and Development Program (SERDP), Project RC-1727.

Lichvar, R., D. Cate, C. Photos, L. Dixon, B. Allen, and J. Byersdorfer. 2009. Vegetation and channel morphology responses to ordinary high water discharge events in arid west stream channels (No. ERDC/CRREL TR-09-5). Engineer Research and Development Center. Hanover, NH: Cold Regions Research and Engineering Lab.

Méndez-Barroso, L. A., E. R. Vivoni, C. J. Watts, and J. C. Rodríguez. 2009. Seasonal and interannual relations between precipitation, Surface soil moisture and vegetation dynamics in the North American monsoon region. Journal of Hydrology. 377(1):59-70. doi:10.1016/j.jhydrol.2009.08.009

Nguyen, U., E. P. Glenn, P. L. Nagler, and R. L. Scott. 2014. Long-term decrease in satellite vegetation indices in response to environmental variables in an iconic desert riparian ecosystem: the Upper San Pedro, Arizona, United States. Ecohydrology. doi:10.1002eco.1529.

Nicholson, S. E., and T.J. Farrar. 1994. The influence of soil type on the relationships between NDVI, rainfall, and soil moisture in semiarid Botswana. I. NDVI response to rainfall. Remote Sensing of Environment 50(2):107-120. doi:10.1016/0034-4257(94)90038-8.

NOAA. n.d. Pacific Marine Environmental Laboratory: Tropical Atmosphere Ocean project: El Niño Theme Page. Retrieved March, 2015. (www.pmel.noaa.gov/tao/elnino/faq.html\#deal).

Ogle, K., and J. F. Reynolds. 2004. Plant responses to precipitation in desert ecosystems: integrating functional types, pulses, thresholds, and delays. Oecologia 141(2):282-294. doi: 10.1007/s00442004-1507-5.

Petrie, M. D., S. L. Collins, D. S. Gutzer, and D. M. Moore. 2014. Regional trends and local variability in monsoon precipitation in the northern Chihuahuan Desert, USA. Journal of Arid Environments 103:63-70. doi:10.1016/j.jaridenv.2014.01.005. 
Pettorelli, N., J. O. Vik, A. Mysterud, J.M. Gaillard, C.J. Tucker, and N. C. Stenseth. 2005. Using the satellite-derived NDVI to assess ecological responses to environmental change. Trends in Ecology \& Evolution 20(9):503-510. doi:10.1016/j.tree.2005.05.011.

Qi, J., A. Chehbouni, A. R. Huete, Y. H. Kerr, and S. Sorooshian. 1994. A modified soil adjusted vegetation index. Remote Sensing of Environment 48(2):119-126. doi:10.1016/0034-4257(94)90134-1

R Core Team. 2014. R: A language and environment for statistical computing. R Foundation for Statistical Computing. Vienna, Austria. Retrieved October 7, 2014. (http://www.R-project.org/).

Richard Y., and I. Poccard. 1998. A statistical study of NDVI sensitivity to seasonal and interannual rainfall variations in Southern Africa. International Journal of Remote Sensing 19(15):2907-2920. doi: 10.1080/014311698214343.

Shaw, J. R., and D. J. Cooper. 2008. Linkages among watersheds, stream reaches, and riparian vegetation in dryland ephemeral stream networks. Journal of Hydrology 350(1):68-82. doi:10.1016/j.jhydrol.2007.11.030.

Snyder, K. A., and S. L. Tartowski. 2006. Multi-scale temporal variation in water availability: implications for vegetation dynamics in arid and semi-arid ecosystems. Journal of Arid Environments 65(2):219234. doi:10.1016/j.jaridenv.2005.06.023.

Stromberg, J. C., V. B. Beauchamp, M. D. Dixon, S. J. Lite, and C. Paradzick. 2007. Importance of low-flow and high-flow characteristics to restoration of riparian vegetation along rivers in arid south-western United States. Freshwater Biology 52(4):651-679. doi:10.1111/j.1365-2427.2006.01713.x.

Sutfin, N. A., J. R. Shaw, E. E. Wohl, and D. J. Cooper. 2014. A geomorphic classification of ephemeral channels in a mountainous, arid region, southwestern Arizona, USA. Geomorphology 221:164-175. doi:10.1016/j.geomorph.2014.06.005

Svoray, T., and A. Karnieli. 2011. Rainfall, topography and primary production relationships in a semiarid ecosystem. Ecohydrology 4(1):56-66. doi:10.1002/eco.123.

Vogelmann, J. E., B. Tolk, and Z. Zhu. 2009. Monitoring forest changes in the southwestern United States using multitemporal Landsat data. Remote Sensing of Environment 113(8):1739-1748. doi:10.1016/j.rse.2009.04.014.

Wang, X., H. Xie, H. Sharif, and J. Zeitler. 2008. Validating NEXRAD MPE and Stage III precipitation products for uniform rainfall on the Upper Guadalupe River Basin of the Texas Hill Country. Journal of Hydrology 348(1): 73-86. doi:10.1016/j.jhydrol.2007.09.057.

Wang, J., P.M. Rich, and K. P. Price. 2003. Temporal responses of NDVI to precipitation and temperature in the central Great Plains, USA. International Journal of Remote Sensing 24(11):2345-2364. doi:10.1080/01431160210154812.

Western Regional Climate Center. 2012. Yuma Proving Ground (029654). Period of record monthly climate summaries. Retrieved from http://www.wrcc.dri.edu/cgi-bin/cliMAIN.pl?azyupg (Accessed November 20, 2014). 